\title{
O Conto da Aia, de Margaret Atwood (1985): Antiutopia, ovários e uma história social do tempo ${ }^{1}$
}

Juliana C. Zanezi ${ }^{*}$

Resumo: Característico de um movimento literário distópico e de finais da Guerra Fria, O Conto da Aia nos introduz à Gilead, um sistema político totalitário baseado na coisificação das mulheres e estipulando seus valores a depender de suas funções biológicas naturalizadas, e que possui características e premissas muito próximas às observadas nos dias atuais. O presente artigo preocupou-se em diagnosticar e qualificar algumas facetas temporais presentes no romance, localizando-o dentro do campo de uma História Social do Tempo que, em linhas gerais, busca analisar as temporalidades que estão contidas no objeto de estudo, bem como aquelas nas quais o objeto se situa. Com isso, selecionamos três principais direções para melhor entendimento do romance: a estruturação de uma distopia anti-utópica de Gilead, que é uma espécie de teocracia cristã do século XX; os tempos biológicos humanos, principalmente femininos; e os usos do passado e da História dentro do romance. Para tanto, dialogamos com diversos autores familiares ao gênero de ficção científica, distopias e história dos conceitos, além de artigos sobre feminismo e suas facetas, relógios biológicos e literatura.

Palavras-Chave: tempo, literatura, ficção-científica, feminismo, distopia

1Este artigo é fruto das discussões realizadas na disciplina de História Social do Tempo ministrada no Departamento de História da USP pelo professor João Paulo Garrido Pimenta, a quem agradeço a paciência e atenção nas leituras e apontamentos. Também cabe agradecimentos imensos às leituras cuidadosas e contribuições preciosas de Cristiane e Maristela.

*Graduanda em História pela Universidade de São Paulo. Pesquisadora do Laboratório de Estudos sobre o Brasil e o Sistema Mundial (LabMundi-USP). Contato: juliana.zanezi@usp.br 


\section{artigos}

Juliana C. Zanezi

\section{Introdução}

O chamado gênero "ficção científica" dentro da literatura mundial vem sendo construído desde o século XIX, com Frankenstein, de Mary Shelley, publicado em 1818. Porém, é no início da segunda metade do século XX que este tipo de ficção é consolidada enquanto gênero literário, sendo seus grandes pilares autores "veteranos" oitocentistas como Júlio Verne (Viagem ao Centro da Terra, 1864) e H.G. Wells (A Máquina do Tempo, 1895), passando por Isaac Asimov (Fundação, 1951) e Arthur C. Clarke (O Fim da Infância, 1953) e Ray Bradbury (Fahrenheit 451, 1953), até Philip K. Dick (Androides sonham com ovelhas elétricas?, 1968). Estes autores seguiram principalmente pelas questões de tecnologia, viagem no tempo, o espaço sideral, robótica e impérios intergalácticos, porém, sempre traduzindo as grandes inquietações acerca do mundo em que viviam. Paralelamente, temos a linha de autores como Yevgeny Zamyatin (Nós,1920), Aldous Huxley (Admirável Mundo Novo, 1932) e George Orwell $(1984,1949)$, com distopias histórico-políticas e catástrofes humanas, algo voltado mais para as inquietações políticas e intelectuais, a psique do homem na instabilidade política (JAMES; MENDLESOHN, 2003, p.15-17). Todos esses romances têm muito em comum, seja pela inquietude acerca dos tempos históricos nos quais os autores viviam, seja a projeção de um futuro desastre e pouco esperançoso, seja a descrença na humanidade em geral. Além disso, podemos observar que nestes romances do pós-guerras a ameaça nuclear é frequentemente representada, inclusive por meio de sistemas políticos desumanizantes e totalitários.

No entanto, outro ponto comum entre os mesmos é que todos foram escritos por homens europeus ou norte-americanos, brancos. Há de se levar em conta dois pontos sobre essa informação: i) seria sintomático acerca dos leitores e escritores deste horizonte da ficção que, mesmo que este tenha sido fundado por uma mulher, o mesmo foi consolidado e continua ancorado em certo tipo de autor com certos tipos de narrativa? ii) e que as questões levantadas em seus romances, como inquietude e desesperança mencionadas anteriormente, tem caráter universalizante, ou seja, humanidade enquanto um todo praticamente uniformizado sob as mesmas égides sociais? 


\section{artigos | e}

O Conto da Aia, de Margaret Atwood (1985):

Antiutopia, ovários e uma história social do tempo

Estas e outras numerosas questões (por exemplo, como agrupar as diferentes temáticas/questões da sci-fi em correntes ou categorias de acordo com seus tempos históricos) renderiam muitos trabalhos historiográficos acerca da ficção científica em geral, logo não cabe no presente artigo. O que nos interessa dentro dessa perspectiva é a existência de outra corrente da ficção científica, menos lida e comentada que as anteriores e que vem crescendo a partir da década de setenta com autoras célebres como Ursula K. Le Guin ( $A$ Mão Esquerda da Escuridão, 1969), Octavia Butler (Kindred - Laços de Sangue, 1979), Joanna Russ (The Female Man,1975) e, entre outras, Margaret Atwood. Estas autoras propuseram ao sci-fi questões políticas e sociais diversas que até então eram praticamente ignoradas pelos autores anteriores: raça, gênero e orientação sexual tornaram-se as motrizes de suas obras que salientaram diferentes percepções, experiências e projeções de passado, presente e futuro. A leitura destas obras vem principalmente crescendo nos meios feministas e as interpretações e análises enriquecem cada vez mais a construção e debates do gênero da ficção cientifica. O Conto da Aia vem surgindo como um dos maiores expoentes dessa corrente e, felizmente, impulsionando o ramo editorial brasileiro à primeira tradução de algumas obras para o português, como foi o caso de Kindred - Laços de Sangue, traduzido pela editora Morro Branco em 2017; e mesmo a reedição de O Conto da Aia pela editora Rocco no mesmo ano.

Margaret Atwood, a autora da obra analisada neste artigo, nasceu em 1939 em Ottawa. É graduada em literatura pela University of Toronto, tem mestrado na Radcliffe College e ainda diplomas de doutorados honoráveis em diversas universidades. Lecionou e ganhou prêmios na área de literatura fantástica e ficção científica, inclusive o prestigiado Prêmio Arthur C. Clarke para melhores produções de ficção científica. Com mais de quarenta livros publicados entre romances, contos, críticas literárias e livros infantis, Atwood consagrou-se como uma das maiores escritoras do século XX. Atualmente vive em Toronto, lecionando e publicando (MARGARET ATWOOD OFFICIAL WEBSITE, 2017). The Handmaid's Tale é 


\section{artigos}

Juliana C. Zanezi

considerado um sucesso de crítica e de vendas, sendo adaptado para o cinema, teatro, rádio e, em 2017, série de televisão e streaming ${ }^{2}$. A edição brasileira utilizada como fonte e referência neste trabalho é a da Editora Rocco, de 2017, reimpressa devido ao sucesso da série de televisão.

As Aias servem a um, e apenas um, propósito: procriação. Seus ovários sadios viraram recurso natural de Gilead, receptáculos das "sementes" para geração de crianças saudáveis para casais de oficiais sem filhos. Em um quadro onde há grande queda de natalidade causada por extrema exposição à radiação nuclear, elas são uma "riqueza da nação". O Conto da Aia é um romance escrito pela canadense Margaret Atwood publicado em 1985, que revela a história da aia Offred e sua significativa trajetória dentro da República de Gilead, uma teocracia cristã do século XX que tomou o poder por via de um golpe. Os Estados Unidos da América dão lugar a um sistema cristão, autoritário e violento, que coisifica as mulheres controlando suas funções e direitos de acordo com pressupostos principalmente bíblicos levados ao pé da letra.

Offred descreve, em primeira pessoa, variadas situações como Aia: deveres cotidianos, rituais de orações e expurgos, violências que sofre e observa, Cerimônias (ato sexual com o Comandante) e, simultaneamente, suas memórias. Seus dias são compostos de poucas atividades e muita espera, sem saber o que vai acontecer, sem perspectiva de emancipação, sem nenhuma função na sociedade além de gerar uma criança saudável, o que, aliás, pode nunca acontecer.

A proposta deste artigo é analisar as diversas concepções de tempo contidas neste romance, muito revisitado pela crítica literária, direito, sociologia, estudos de gênero, dentre

2As adaptações mais notáveis: O filme de produção alemã, de 1990, que conta com elenco de peso como Faye Dunaway e Robert Duvall. Foi traduzido no Brasil como "Decadência de uma Espécie". Mais informações: http://www.imdb.com/title/tt0099731/. A série de televisão é de 2017 e produzida pela Hulo. Ainda está em andamento e promete próxima temporada que escapa aos eventos que ocorrem no romance. Recebeu setenta e uma indicações à prêmios de televisão, ganhando quarenta deles. Mais informações: http://www.imdb.com/title/tt5834204/. 


\section{artigos |e}

O Conto da Aia, de Margaret Atwood (1985):

Antiutopia, ovários e uma história social do tempo

outras $^{3}$. Porém, no meio historiográfico pouco ou quase nada pode ser encontrado a seu respeito. Portanto, é importante mencionar que esta é uma obra que pode ser uma fonte histórica profícua, inclusive pelas distintas temporalidades ficcionais que apresenta, bem como dos tempos nos quais foi escrita, publicada, adaptada e reeditada. Três de seus aspectos ficcionais podem nos servir à análise: a estruturação de uma distopia anti-utópica; os tempos biológicos, principalmente femininos; e, por fim, os usos do passado e da História dentro do romance. Esta análise se valerá da perspectiva de História Social do Tempo, no qual as temporalidades contidas numa fonte são evidenciadas na análise, inspirada pelos escritos do historiador alemão Reinhart Koselleck.

Para pensarmos noções de tempo neste e em qualquer romance, temos que levar em conta que o tempo da literatura é essencialmente um tempo "humano", ou seja, compreendido apenas dentro de um contexto e visão de mundo experimentados social e historicamente. Um tempo, portanto, distinto daqueles da natureza. É um tempo pessoal, psicológico, privado. Sem dúvida, a questão da memória também é essencial na formação de uma narrativa literária, principalmente tratando-se aqui de um escrito em primeira pessoa do singular. A centralidade da perspectiva de um indivíduo só é compreendida pela associação com seu contexto e "universo", gerando uma construção direcionada; afinal, a literatura sempre pintou o indivíduo como centro das forças ativas e dinâmicas, "capazes ou incapazes de controlar, sintetizar e organizar os elementos heterogêneos da experiência humana numa

\footnotetext{
3Alguns exemplos de diversidade dos trabalhos sobre o romance, mas existem inúmeros mais: COOPER, Pamela. Sexual Surveillance and Medical Authority in Two Versions of The Handmaid's Tale. The Journal of Popular Culture, ed.28, vol.4, 2004, p. 49-66. Disponível em: http://onlinelibrary.wiley.com/wol1/doi/10.1111/j.00223840.1995.498449.x/abstract. DIETZ, Mary G. Context Is All: Feminism and Theories of Citizenship. Daedalus, vol. 116, no. 4, 1987, pp. 1-24. Disponível em: www.jstor.org/stable/20025121. DODSON, DANITA J. 'We Lived in the Blank White Spaces': Rewriting the Paradigm of Denial in Atwood's The Handmaid's Tale. Utopian Studies, vol. 8, no. 2, 1997, pp. 66-86. Disponível em: www.jstor.org/stable/20719685. GOTSH-THOMSON, Susan. The Integration of Gender into the Teaching of Classical Social Theory: Help from 'The Handmaid's Tale'. Teaching Sociology, vol. 18, no. 1, 1990, pp. 69-73. Disponível em: www.jstor.org/stable/1318234. HAMMER, Stephanie Barbé. The World as It Will Be? Female Satire and the Technology of Power in 'The Handmaid's Tale'. Modern Language Studies, vol. 20, no. 2, 1990, pp. 39-49. Disponível em: www.jstor.org/stable/3194826.
} 


\section{artigos}

Juliana C. Zanezi

unidade, estrutura e identidade funcional denominada personagem." (MEYERHOFF, 1976, p. 31).

Ao adentrar no romance, é necessário esclarecer alguns pontos preliminares sobre suas personagens para permitir comentários mais claros. Primeiramente, "Offred" constitui um patronímico formado por of (do inglês, "de") e o nome do Comandante. Assim, Offred seria a aia pertencente a Fred, e não uma mulher específica. Nossa protagonista já teve outro "nome", mas por vir a morar na casa do Comandante Fred, passa a ser unicamente associada a ele. Por exemplo, na trama a protagonista conhece três Ofglen ("Of Glenn") diferentes, uma substituída após a outra. As Aias perderam até o direito a seu nome próprio. As Martas são mulheres em condições análogas, porém com funções bem diferentes: ser as servas das casas dos Comandantes. Estes, por sua vez, são os oficiais do alto escalão do regime gileadiano e vivem nas partes das cidades cercadas por muros. Cada Comandante tem sua Esposa e, quando estas são inférteis, demandam uma Aia.

\section{GILEAD: UTOPIA, ANTI-UTOPIA E A DISTOPIA}

As utopias são ideias acerca do mundo que designam ou uma completa loucura ou a esperança absoluta, permeando os recônditos da imaginação humana de forma muito longeva. Em geral, traduzem projetos de futuro para os seres humanos, tanto no plano material, quanto no espiritual ou cósmico. Platão e Thomas Morus, separados por mais de dois mil anos, tem algo em comum: concepções de utopia. Mesmo que de formas distintas, estas são os "não lugares", ou seja, que não existem empiricamente, mas poderiam vir a existir. A construção das utopias consiste em uma crítica ao presente do autor e sua realidade. Em outras palavras, um plano ou projeto a ser perseguido, visando sucessos políticos, econômicos e religiosos, etc., que são desejáveis no momento que uma utopia é concebida. Torna-se mais uma ideia de futuro perfeito do que um lugar propriamente dito (MUMFORD, 2007, p.57). 


\section{artigos |e}

O Conto da Aia, de Margaret Atwood (1985):

Antiutopia, ovários e uma história social do tempo

Se as utopias podem traduzir uma sensibilidade positiva em relação ao futuro, as chamadas "distopias" sempre revelam o pessimismo com o mesmo, podendo inclusive ser tratadas como uma "modalidade" de utopia, decididamente negativas. O Conto da Aia entra nessa concepção e numa tradição literária de desesperança com o futuro das estruturas políticas, religiosas e sociais. Gilead não é apenas um sistema patriarcal violento e autoritário distante: nele, percebe-se claramente a degeneração extrema de situações e quadros que já observamos até nos dias atuais, transformando-se incontrolavelmente em um totalitarismo.

Um dos pontos mais importantes na presente análise é que neste romance temos o curioso caráter frágil e delimitado da República de Gilead, sendo a mesma restrita e finita dentro do próprio romance. Em primeiro lugar em relação ao espaço. Uma passagem que exemplifica esta limitação é encontrada no capítulo quinto, quando

Um grupo de pessoas caminham na nossa direção. São turistas e parecem japoneses[...]. As mulheres oscilam sobre os saltos altos [...], suas cabeças estão nuas, o cabelo excessivamente visível em sua escuridão e sexualidade. [...]. Sentimos fascínio e também repulsa. Em tão pouco tempo nossas cabeças mudaram tanto com relação a esse tipo de coisa. [...] - eles querem saber se vocês são felizes - diz o interprete. Posso imaginar a curiosidade deles. Elas são felizes? Como podem ser felizes? (ATWOOD, 2017, p. 39-40).

O território gileadiano cobre a maior parte do que seriam os Estados Unidos e ainda locais chamados de "Colônias", dos quais temos poucas informações, nenhuma relacionada à sua localização; existe possível escapatória deste sistema ao sair do país, mesmo que ilusórias e praticamente impossíveis para qualquer mulher. As aias de Gilead são motivo de fascinação por parte de turistas, pois os mesmos não conheciam nada parecido. A própria Offred ironiza: “Somos secretas, proibidas, algo que excita." (ATWOOD, 2017, p. 41).

Em segundo lugar, essa restrição se dá temporalmente. Tudo começa com um golpe, do qual nossa protagonista só conhece o que vê pela televisão e conta 


\section{artigos}

Juliana C. Zanezi

Foi depois da catástrofe, quando o Presidente foi morto a tiros e o Congresso metralhado. O Exército decretou estado de emergência. Na época botaram a culpa nos fanáticos muçulmanos. [...]. Como é que eles tinham entrado, como é que tinha acontecido? Foi então que suspenderam a Constituição [...] (ATWOOD, 2017, p.41)

Logo após essa "catástrofe", supostamente devido a um ataque muçulmano, há uma espécie de intervenção militar; porém "não era O exército. Era outro exército." (ATWOOD, 2017, p. 215), dando a entender que não foram as forças militares nacionais atuando, mas uma força paralela. Nossa narradora conta que foi dispensada de seu emprego na biblioteca da cidade quando homens armados e fardados forçavam uma "nova lei" que determinava que nenhuma mulher poderia ter um emprego. Além disso, sua conta bancária e bens foram congelados. As contas femininas foram transferidas para os maridos ou parentes homens mais próximos, e a sua passa a pertencer a seu marido, Luke. A restrição da autonomia das mulheres não veio apenas com objetivos puramente ideológicos ou religiosos, mas também pragmáticos. A baixa taxa de natalidade, devido a vazamentos e envenenamentos radioativos, práticas de anticoncepcionais e abortos, além da alta mortalidade infantil, teriam gerado um problema de esgotamento demográfico. As mulheres então seriam realocadas nesse sistema e, no caso de se tornarem Aias, se converteriam numa espécie de recurso natural a ser explorado em prol do "bem" da nova nação que surgia.

Não sabemos quanto tempo passou entre o golpe e os acontecimentos narrados, e mesmo a narradora não parece se importar com isso. Mas pelas "Notas Históricas" que constituem o epílogo do romance, o leitor é introduzido, com estranhamento, ao "12 Simpósio de Estudos Gileadianos", no qual há a revelação que Gilead acabou. Neste epílogo, são dadas várias informações que são preciosas para entendimento da obra, como a natureza do golpe do grupo paramilitar "Filhos de Jacó", os motivos mais ou menos reais (na ficção) da infertilidade e formação das estruturas ideológicas e políticas daquele sistema. Além disso, tomamos conhecimento que qualquer que tenha sido o destino de Offred, ele permanece desconhecido. Porém sua história (e, portanto, os capítulos lidos) foi registrada 


\section{artigos}

O Conto da Aia, de Margaret Atwood (1985):

Antiutopia, ovários e uma história social do tempo

por ela em cerca de trinta fitas cassetes que foram encontradas em escavações arqueológicas no estado do Maine, lacradas dentro de um armário militar. Todo o resto dessa circunstância é mistério. Portanto temos, primeiramente, grandes expectativas negativas sobre o futuro, mas ao final do romance uma resolução deste conflito dá um tom aparentemente otimista. Mas é justamente o contrário. Contudo, esse epílogo acaba por aumentar as problemáticas temporais da fonte, e para essas "Notas Históricas" tecerei comentários especiais mais adiante.

Assim, Gilead teve uma ascensão e desenvolvimento, mas encontrou seu fim em algum momento bem antes do ano de 2195, quando o mencionado simpósio aconteceu. Daí tiramos o "novo" desta construção distópica; afinal, tradicionais distopias, como as consagradas Admirável Mundo Novo (Aldous Huxley, 1932), Nós (Yevgeny Zamyatin, 1921) e 1984 (George Orwell, 1949), estabelecem uma noção aparentemente eterna, infindável e contínua dos terrores causados e o inexorável poder da estrutura totalitária e opressiva na qual se ambientam, enquanto O Conto da Aia já concretiza, dentro do romance, o final do sistema de Gilead.

Gregory Claeys define que O Conto da Aia é "pós-totalitarista", parte de um movimento do pós-guerras no qual as preocupações principais passam a ter relação com a era da energia nuclear, radiação, mudanças climáticas e degeneração cultural em detrimento das ideias hedonistas do consumo desenfreado (CLAEYS, 2017, p.475-476). Por suas definições deste campo, o romance de Atwood não seria apenas uma distopia, mas também uma anti-utopia: ao mesmo tempo que leva o leitor a um lugar que extrapola o que há de ruim hoje, também tem a ideia de claramente denunciar utopias. (CLAEYS; LYMAN, 1999, p, 1-5)

Fiona Tolan afirma que a visão de utopia de Atwood é muito semelhante à do teórico do pós-modernismo Jean-François Lyotard e seu trabalho de 1986, Defining the Postmodern, que associa diretamente as utopias aos totalitarismos e a decadência da confiança no progresso 


\section{artigos}

Juliana C. Zanezi

humano dado pelos últimos séculos: nenhum dos regimes, políticos e econômicos, liberais ou marxistas que emergiram nos séculos XIX e XX, estariam livres da suspeita de conduzirem a genocídios e crimes contra a humanidade. Assim, as utopias seriam os meios mais perigosos de teorizar o futuro por sua facilidade em se transformar em distopia totalitária (TOLAN, 2006, p. 19-20).

Se o pensamento político utópico articula carências que um grupo entende como suas e projeta circunstâncias nas quais as mesmas não existiriam, em teoria, poderia ser uma especulação de cunho positivo. Neste caso, esses elementos de utopia foram mobilizados em O Conto da Aia não apenas para falar sobre o totalitarismo cristão, mas também sobre questões feministas efervescentes no momento de concepção da obra. Assim, sendo, é sabido que os anos oitenta foram um momento de reinvenção do movimento feminista, marcando o fim da chamada "Segunda Onda" que, afinal, desde que surgiu nos anos sessenta, já trazia no seu interior muitas divergências. Estas desembocam na constituição da "Terceira Onda", caracterizada por ser um movimento de maior diversidade, com representantes como Angela Davis e outras teóricas negras, lésbicas, latinas, indianas, etc. que já começam a apresentar o feminismo interseccional, inicialmente o "Black Feminism", cuja crítica coletiva se voltou de maneira radical contra o "feminismo hegemônico" (HIRATA, 2014, p.62).

O feminismo "hegemônico" considera o sexismo a maior das opressões, desconsiderando questões de classe, etnia e orientação sexual em geral. Suas proposições acabaram tornando parte deste movimento branco, heterossexual e focado em realidades dos Estados Unidos, marginalizando as mulheres de outras partes do mundo, assim como negras, latinas e asiáticas, ignorando os outros tipos de opressão como racismo, LGBTfobia, questões de intolerância religiosa, etc. (THOMPSON, 2002, p. 318). Assim, a utopia do feminismo "hegemônico" constituiria uma equidade com os homens que parte de um ponto 


\section{$\operatorname{artigos} \mid \mathrm{e}$}

O Conto da Aia, de Margaret Atwood (1985):

Antiutopia, ovários e uma história social do tempo

de vista baseado em direitos individuais, e não de justiça e transformação da sociedade capitalista e racista por completo.

Voltando ao romance, é importante frisar que o território compreendido pela República de Gilead corresponde aos Estados Unidos da América, tomado por vias de golpe militar. Além disso, é possível que todas as pessoas de Gilead fossem brancas, pois os chamados "Filhos de Cam" (em referência ao livro de Gênesis e Noé) foram perseguidos, expulsos ou executados. No entanto, esta questão fica um pouco dúbia, pois esta alcunha tanto pode ser associada às pessoas negras ${ }^{4}$, mas também é correntemente utilizada ao tratar de islâmicos como "camitas". Ou seja, pode depender da leitura que Atwood fez do termo no momento de escrita da obra. Em todo caso, é certo que não há islâmicos em Gilead, já que seus idealizadores empreitaram uma perseguição religiosa contra praticantes de outras religiões como a muçulmana, quaker, judaica, católicas e outras não cristãs. As pessoas LGBT+ (Lésbicas, Gays, Bissexuais, Travestis, Transexuais, Transgêneros, Queers, Assexuais, Interssexuais e outros que não se identificam em nenhuma dessas terminações) condenados como "traidores do gênero", afinal, segundo os preceitos bíblicos, são abominações. Logo, para boa parte das pessoas moradoras deste local antes do golpe, esse sistema gileadiano é um pesadelo. Todos esses grupos foram perseguidos e executados em praça pública. Porém, para outras pessoas, isso poderia significar um bem-estar social e destaque, paradoxalmente, para as mulheres brancas. Justapondo flashbacks do passado de Offred que fazem referência à movimentação feminista norte-americana dos anos sessenta, a protagonista acaba por revelar que Gilead atende a algumas demandas feministas (com este termo em si nunca mencionado no romance), porém, deformadas e corrompidas.

40 livro de Gênesis conta em seu capítulo nono que Noé amaldiçoou seu filho mais novo Cam após este vê-lo nu e embriagado. Seus descentes iriam servir os descendentes de seus irmãos; e seus descendentes também carregariam a "marca desta maldição na pele". Em seguida, no capitulo décimo, os descendentes de Cam voltamse para o oriente e África edificando línguas, terras e nações naqueles locais. Inclusive esta passagem foi utilizada como forma de legitimação teológica da escravização de africanos a partir do século XV. Para mais informações: MAXWELL, John F. Slavery and the Catholic Church: The History of Catholic Teaching Concerning the Moral Legitimacy of Institution of Slavery. Londres: Barry Rose Publishers, 1975. 


\section{artigos}

Juliana C. Zanezi

Temos um sistema que, como o feminismo "hegemônico", também não leva em consideração outros fatores sociais além da diferença de sexo, colocando ainda as mulheres brancas em posição hierarquicamente superior em relação a todas as outras e, segundo a visão dos idealizadores de Gilead, sem que sofram nenhuma opressão. São muitos os momentos no romance nos quais há distorção proposital de algumas demandas e conceitos do movimento feminista sessentista. Abriu margem para muitas interpretações e escritos em diversas plataformas, acadêmicas ou não, especialmente sobre essas estruturações do enredo de O Conto da Aia. Há análises que argumentam que Atwood é antifeminista (e isso um motivo de descontentamento); há interpretações que usam seus modelos da narrativa para justificar o antifeminismo; há ainda aquelas interpretações, tendencialmente mais corretas, de que Atwood traz críticas ao feminismo "hegemônico" que comentamos anteriormente e o caráter do mesmo. Assim, mesmo que não o diga, Atwood é essencialmente parte do movimento feminista interssecional em construção na década de oitenta.

As personagens que mais transparecem essa deturpação do utópico feminista são as Tias do "Centro Raquel e Lia", o local onde as moças eram disciplinadas e condicionadas à função de aias. Por exemplo, uma distorcida e grotesca subversão intencional do agir com "sororidade" ${ }^{5}$ é apresentada durante discursos ideológicos com fins pedagógicos por parte das disciplinadoras, chamadas "Tias" durante uma espécie de "treinamento de aias", por vezes, como "tentem pensar na situação pelo ponto de vista delas [Esposas], dizia, com as mãos apertadas. Não é fácil para elas." (ATWOOD, 2017, p.23) e,

Paras gerações que vierem depois, dizia Tia Lydia, será tão melhor. As mulheres viverão juntas em harmonia, todas uma única família, vocês serão como filhas para elas e, quando o nível da população voltar a subir de acordo com as expectativas, não precisaremos transferir vocês de uma casa pra outra porque haverá mulheres o suficiente. [...] Mulheres unidas com um fim

5SORORIDADE, do latim "soror" (irmã), é o equivalente a "fraternidade", do latim "fraternitas" (irmão). Ou seja, sororidade é um sentimento e ação entre mulheres, apoiando e se cuidado mutuamente dentro de um sistema que as oprime. Ver: SARAIVA, F. R. dos Santos. “Novíssimo Dicionário Latino-Português: etimológico, prosódico histórico, mitológico, biográfico, etc.". Rio de Janeiro: Livraria Garnier. 10ªed, p. 503 e 1114. 


\section{artigos |e}

O Conto da Aia, de Margaret Atwood (1985):

Antiutopia, ovários e uma história social do tempo

comum! Ajudar umas às outras em suas tarefas cotidianas enquanto percorrem seu caminho na vida juntas. Suas filhas terão maior liberdade. (ATWOOD, 2017, p. 195).

No primeiro trecho, Offred conta como as Tias aconselhavam as aias para considerarem a posição das Esposas como "difícil". É irônico: Aias que tinham seus corpos usados e descartados, não podiam ter acesso a nenhum familiar, não tinham direito de ir e vir ou de hobbies, nem mesmo podiam ser amigas entre si, e ainda perdiam sua identidade... E a posição difícil era a da Esposa? Atwood está claramente criticando como o feminismo hegemônico desconsiderava as questões de opressão de classe/categoria social: 0 argumento é de que se o sexismo "não existe mais", então as mulheres são todas iguais. Mas é claro que não é assim. As Aias e Martas nunca serão equivalentes às Esposas, mas para Tia Lydia todas seriam iguais e viveriam em "harmonia", mesmo que as primeiras fossem servas das últimas, considerando a servidão como "ajuda mútua". Há vários trechos no romance nos quais todas as mulheres são tratadas como um único tipo, sendo que na verdade há essas categorizações que determinam funções e direitos. E claro, como já mencionamos acima, todas as mulheres deste sistema são brancas, com as Tias desconsiderando toda a perseguição ocorrida aos negros e a outras identidades não-brancas.

Outro personagem que traz esse aspecto à tona é ninguém menos que o próprio Comandante. Ele acredita realmente que tudo que os idealizadores e executores do sistema gileadiano fazem às mulheres é o melhor para elas:

Demos-Ihes mais do que tiramos, disse o Comandante. Pensem nas dificuldades que tinham antes. [...]. Algumas delas [mulheres] ficavam desesperadas, passavam fome para ficarem magras, enchiam os seios de silicone [...] Da maneira como fazemos, estão protegidas e podem realizar seu destino biológico em paz. (ATWOOD, 2017, p.260-261).

O Comandante, ao argumentar sobre os benefícios de Gilead para as mulheres, traz alguns argumentos com situações notáveis e características na vida cotidiana de muitas mulheres no mundo real - desde violências domésticas, traição por parte dos parceiros, 


\section{artigos}

Juliana C. Zanezi

perigo ao andar por ruas, os sacrifícios ao tentar atingir padrões de beleza socialmente impostos pela mídia e revistas de "moda e beleza". São mais demandas feministas atendidas de forma tenebrosa, pois em Gilead realmente não existem mais revistas, padrões da moda, corporais ou de beleza e para ele isso significa que todas as mulheres "tem um homem com facilidade".

Gilead é uma sociedade que superestima valores tradicionais, e a fala do Comandante defende que, no sistema antecessor (que seria então, antes do golpe de Gilead), as mulheres tivessem dificuldades para cumprir o tal "destino biológico", no qual sexo e o gênero binários são naturalizados. O que ele quer dizer é que as reivindicações do feminismo teórico que começou a questionar esses fatores no pós-guerras atrapalhou as mulheres. Havia um determinismo biológico ficcional construído ao longo da história e que agora em Gilead era resgatado; logo, as mulheres podem voltar a cumprir suas únicas funções: a reprodução e quaisquer outras dadas na esfera doméstica.

Finalmente, a ficção distópica vem para subverter as normas e certezas da utopia tradicional, expondo as contradições nos aspectos políticos e sociais do "sonho" utópico, trazendo sob os holofotes o autoritarismo que idealizadores utopistas tentam disfarçar, ignorar ou mesmo esconder. Com sádica ironia, Atwood mobilizou elementos da narrativa distópica de forma a denunciar não apenas as práticas misóginas e o totalitarismo cristão, mas também alerta sobre perigos da facilidade da degeneração de uma determinada faceta do movimento feminista da Segunda Onda. Suas demandas foram "atendidas", mas em contrapartida, o foram pelas mãos de seus próprios opressores e sendo utilizadas contra elas.

\section{O TEMPO, O SEXO E OS OVÁRIOS}

Na primeira fase da história de Gilead, as mulheres solteiras, viúvas ou que tiveram seus casamentos deslegitimados (como Offred), foram separadas em categorias: as Aias, que servem os Comandantes para procriação; e as Martas, que são como criadas das casa dos 


\section{artigos}

O Conto da Aia, de Margaret Atwood (1985):

Antiutopia, ovários e uma história social do tempo

mesmos. Essa categorização é feita de acordo com a fase de cada mulher dentro de seu ciclo reprodutivo, ou seja, se podem ou não ter filhos: geralmente as mais jovens, que são férteis e saudáveis, capazes de gerar crianças, tornam-se Aias, enquanto as mais velhas e doentes, ou com trompas ligadas ou laqueadura, são Martas.

Como é sabido, em todos os organismos, sejam humanos ou não, encontramos uma série de processos que se repetem em padrão similar e que determinam a frequência de necessidades, como fome, sono, humores, atividade sexual, etc., sendo que a maior parte destes tempos são cíclicos e compõem o ramo de estudo da cronobiologia. Esses processos estão sendo constantemente regulados pelos chamados relógios biológicos, conformando e pautando boa parte de nossas atividades diárias. Não parece haver um relógio próprio em totalidade do organismo, mas uma simultaneidade deles mais ou menos sincronizados (ESPINOZA; VARGAS, 2013, p. 5).

Partindo da constatação de que a temporalidade dos ciclos biológicos é essencial para a compreensão de como os seres humanos organizam suas atividades, as mulheres biologicamente dotadas de um sistema reprodutor feminino possuem um tempo diferenciado: o "tempo do útero". O desenvolvimento reprodutivo de uma mulher tem início, meio e fim. Sendo, no entanto, ciclicamente linear, já que seu andamento é dado por inúmeros processos menores: os ciclos menstruais. Parece óbvio refletir que as Cerimônias (ato sexual com o Comandante) ocorriam de acordo como estabelecido pelo ciclo menstrual individual e ingovernável (mas previsível) de cada Aia, em datas de período fértil. Mesmo que esse ciclo dite quando essas Cerimônias ocorrem, é notável que em nenhum momento do livro haja menção da palavra "menstruação". Não fica claro se há definição arbitrária de uma data para a Cerimônia ou se há algum conhecimento ou controle de cada aia, mas há um capítulo inteiro dedicado à ida de Offred ao ginecologista. 


\section{artigos}

Juliana C. Zanezi

O "tempo do útero" tem início na puberdade, com a menarca, a primeira menstruação. Os ciclos da menstruação são mensais e são apenas interrompidos pelo tempo da gestação, cerca de nove meses do calendário gregoriano; constituem uma novidade, um evento extraordinário significativo e cheio de importância, mas que não dura. Tanto uma gravidez de sucesso, como aquela interrompida, apenas as consequências são observadas com o desenrolar do tempo; e, ao "final" do processo, a menopausa. Esses processos biológicos regem boa parte das vidas femininas no mundo real e em Gilead, onde os mesmos são intrinsecamente ligados a preceitos ultra religiosos cristãos que determinam um destino biológico e função social da mulher pautada em sua capacidade ou não de ter filhos. Em Gilead, a história bíblica de Jacó, Lia e Raquel é o principal "modelo" para os usos das mulheres enquanto Aias, como veremos mais adiante.

Vale frisar, que o chamado "tempo do útero" não é uma regra - muito pelo contrário. Nos dias atuais, muitos elementos interferem nesse processo: anticoncepcionais em geral, abortos espontâneos ou não, questões ambientais, alimentares e farmacológicas são alguns fatores que podem alterar, acelerar ou até parar os ciclos, positiva ou negativamente. O importante desta colocação é que organismos humanos femininos "naturalmente" possuem estes atributos. Porém, não estamos aqui advogando pela naturalização ou romantização destes processos, inclusive da gestação: a determinação da gestação e procriação como função social da mulher há tempos já é fortemente desconstruída, bem como a romantização da maternidade.

Porém, é importante mencionar que no romance apenas mulheres cisgênero, ou seja, aquelas que ao nascerem foram consideradas do sexo feminino e identificam-se com o gênero feminino, são alvo da categorização Aia/Marta. Afinal, decorre que para o sistema de Gilead, qualquer designação de gênero que não seja a cisnormativa, foi considerada abominação e, portanto, foram perseguidas e executadas. A autora pouco adentra nessa esfera, porém um exemplo análogo é Moira: a melhor amiga da protagonista antes do golpe, 


\section{artigos | e}

O Conto da Aia, de Margaret Atwood (1985):

Antiutopia, ovários e uma história social do tempo

era assumidamente lésbica. Com a tomada de poder pelos Filhos de Jacó, ela se vê obrigada a ocultar sua homossexualidade para sobreviver. Claro que para alguns grupos do espectro LGBT+ tal ocultação não seria possível por diversas questões, mas há de se considerar que se o sistema gileadiano segue preceitos cristãos essencialmente do Antigo Testamento de forma ferrenha e ao pé da letra, então toda diversidade seria amputada do regime. Todos seriam "automaticamente" considerados cisgênero e heterossexuais pela planificação violenta de normatividade sexual cristianizada, uniformizando todas as pessoas na "regra" e os que se rebelassem seriam executados como "traidores do gênero". Por fim, apenas mulheres dotadas biologicamente de um sistema reprodutor feminino seriam consideradas "verdadeiras" para Gilead e, logo, passíveis do uso que o regime quis designá-las.

Afinal, prefigura que a autora não negligenciou deliberadamente a questão do cis/transgênero, mas parece levantar algumas questões acerca dos debates interseccionais: "Ser mulher" é apenas possuir útero, trompas, ovários, etc.? Uma mulher é "melhor" ou "pior" por ser capaz ou não de gerar filhos? E "ser mulher" é apenas ter tal capacidade? Pode-se determinar uma mulher por ser casada com um homem ou, ainda, não ser casada com nenhum? "Ser mulher" é ter alguma função social? Essas e outras questões vêm sido enfrentadas pelos feminismos interssecionais e estudos de gênero que avançam cada vez mais na compreensão da sexualidade e gênero de homens e mulheres, buscando fatores não biológicos e/ou biologizantes, distanciando-se largamente de pressupostos religiosos. Enfim, utilizando-se da motriz reprodutiva, a autora levanta questões acerca dos corpos e mentes femininos numa sociedade que as vê como "úteros ambulantes" ao mesmo tempo que tensiona novamente com o feminismo hegemônico e sua "delimitação" do "ser mulher".

Consideramos, por conseguinte, que o "tempo do útero" é o mais importante motor de toda a narrativa de $O$ Conto da Aia. Todas as mulheres deste sistema estão submissas à ele: as Tias geralmente são idosas ou viúvas, portanto seriam o equivalente das Martas nesse 


\section{artigos}

Juliana C. Zanezi

sentido, porém gozam do fato de serem aliadas dos Filhos de Jacó, provavelmente suas familiares que os auxiliaram na montagem do sistema com o uso da religião, como veremos a seguir. As Esposas ao serem privadas de sua capacidade de gestação, submetem-se ao sistema das Aias que, por sua vez, são coibidas a gerarem crianças. Por fim, outro elemento desta trama não trazido até agora são as "Economesposas", isto é, as cônjuges dos outros homens do sistema que não são parte da elite e que não tiveram seus casamentos anulados. Estas mulheres devem servir como Esposas, Aias e Martas aos maridos, cumprindo todas as funções e, mesmo que sejam estéreis seus maridos não possuem direito às Aias. Pouco sabemos dessas figuras, mas a opressão sobre elas parece ser multiplicada ainda mais pela questão de classe: sua e de seus maridos, submetidas a servir nas esferas social, doméstica e sexual.

Enfim, se as múltiplas temporalidades vividas pela sociedade em Gilead são hierarquizadas (assim como em todas as sociedades do mundo real), o "tempo do útero" goza de alta importância nessa cadeia, apesar das mulheres não terem nenhuma autonomia ou direitos sob seus corpos. Ironicamente, são esses tempos que organizam boa parte da sociedade de Gilead, não obstante o horror que isso causa nas vidas das mulheres integrantes daquele sistema.

\section{A PROBLEMÁTICA DA HISTÓRIA, A MEMÓRIA E O FUTURO}

Através dos séculos, o termo "História" passou por diversas mudanças de concepção e entendimento de como encarar o passado, tanto para historiadores quanto para a sociedade em geral. A História como "mestra da vida", ideia bem estabelecida por Cícero é, talvez uma das mais longevas concepções, perdurando até os dias de hoje no imaginário mais geral (KOSELLECK, 2016, p. 44-45). Se o conhecimento do passado traria instruções para presente e futuro, isso inclui os exemplos a não serem seguidos, como não agir, como não deixar as coisas acontecerem. Grande formadora do senso comum acerca da "função da história" no mundo real, também é assim a concepção oficial de história dos idealizadores de Gilead e 


\section{artigos |e}

O Conto da Aia, de Margaret Atwood (1985):

Antiutopia, ovários e uma história social do tempo

seus defensores: é de que os governos e cidadãos comuns de antes do estabelecimento da Nova República, “cometeram erros, diz Tia Lydia. Nós não pretendemos repeti-los.” (ATWOOD, 2017, p. 138).

Tendo isso em vista, as personagens mais envolvidas com o uso do passado para ensinamentos são as Tias do Centro Raquel e Lia. Ele vem para exemplificar como este era hostil às mulheres, como eram agredidas e violentadas, ou seja, fins coercitivos. Por exemplo, ali as meninas eram expostas aos mais variados tipos de lições, agressivas ou condescendentes antes de serem encaminhadas às casas dos Comandantes, como

uma vez por semana tínhamos uma sessão de cinema [...] por vezes a fita que ela exibia era um velho filme pornográfico dos anos setenta ou oitenta. Mulheres ajoelhadas chupando pênis ou armas, mulheres amarradas ou com coleiras de cachorro, [...] mulheres sendo estupradas, surradas, mortas. [...]. Reflitam cuidadosamente sobre as alternativas, dizia Tia Lydia. Vocês veem como costumava ser? Isso era o que pensavam das mulheres na época. [...] (ATWOOD, 2017, p. 145)

Também no Centro Raquel e Lia as moças passam a conhecer os baixíssimos níveis de natalidade e porque são necessárias. Percebemos que o passado referido pelas Tias sempre vem do mais recente, os anos precedentes ao estabelecimento de Gilead. Deduz-se que o passado "recente" seja o considerado contemporâneo para nós (logo, para a autora), os anos de emancipação feminina, feminismo, lutas sociais de todas as minorias, o capitalismo tardio, assim sendo em linhas gerais, o século XX. Estes anos são considerados de subversão:

aqueles anos foram uma anomalia, historicamente falando, disse o Comandante, apenas uma infeliz causalidade. Tudo o que fizemos foi por as coisas de volta no lugar, de acordo com as normas da natureza." (ATWOOD, 2017, p. 261)

O Comandante tem esse período como "anomalia histórica". Fica evidenciado no romance que o mesmo possui quantidade substancial de "materiais heréticos pictóricos e literários", tais artefatos são revistas femininas como a Vogue, roupas de teatro, baralhos, 


\section{artigos}

Juliana C. Zanezi

livros não autorizados... Enfim, coisas que haviam sido proibidas. Com isso, entendemos que sua preocupação com o passado não seja meramente como objeto de um interesse descuidado, excitante; mas também ideológico já que algumas suas falas em referência ao passado sempre o trazem como perigoso às mulheres, anomalia, erro.

Offred demonstra muita sensibilidade em relação a seu passado. É impossível compreender a vida de alguém, seja ficcional ou real, sem reconstruir seu passado com associações significativas transpondo-se aos fatos históricos (MEYERHOFF, 1976, p. 24). Isso é parte de um instrumento narrativo extremamente importante que Atwood torna ainda mais especial, já que Offred nem sempre foi Offred, nem sempre foi aia, nem sempre fez parte de Gilead. Assim, tomamos conhecimento do que aconteceu com uma população toda a partir de seu relato individual, de suas reconstruções, logo, sua memória, sua capacidade de exprimir uma síntese e uma impressão de suas experiências. A própria protagonista admite que seus relatos são reconstruções posteriores, ela tem conhecimento de sua própria subjetividade, de sua própria memória trabalhando e dos erros interpretativos, propensa a reprimir, esquecer, distorcer ou projetar.

Suas reconstruções sobre seu passado antes de Gilead ocorrem, em sua maioria, em partes do livro intituladas "Noite". Entre quinze seções do romance, sete se passam durante períodos noturnos, seu tempo de relativa liberdade, não existente em outros momentos. "A noite é minha, meu próprio tempo, para fazer o que quiser, contanto que fique quieta. [...]. Para onde devo ir? Algum lugar bom" (ATWOOD, 2017, p. 48). Assim, como suas ações estão completamente restritas, essa "liberdade" é ilusória e então ela se volta para seu passado, um "lugar bom", admitindo posteriormente ser uma refugiada nele. Podemos até falar em "três passados" de Offred: primeiramente, sua vida antes de Gilead (esse lugar "bom" o qual ela recorre); em seguida, temos aquele que se dá antes de sua vida como Offred, ou seja, no Centro Raquel e Lia; e por fim, o passado em que se dá a narrativa com a qual temos contato, que para nós parecia seu presente até o epílogo revelar a natureza desse relato. Com isso, 


\section{artigos | e}

O Conto da Aia, de Margaret Atwood (1985):

Antiutopia, ovários e uma história social do tempo

parece haver uma distinção clara entre os variados "eu" de Offred que constituem sua identidade como personagem: uma vida antes de Gilead que não existe mais, uma durante suas funções como aia e, por fim, seu destino misterioso que permanece desconhecido para nós, mas que é possível deduzir que tenha sido de sua fuga do sistema. É significativo que a noite seja também o momento de subversão das regras e traição, do "pecado", com o Comandante solicitando sua presença no gabinete e, posteriormente, o relacionamento de Offred com Nick, motorista da casa.

Outra concepção de passado a ser ressaltada nesta análise é o bíblico. Ora, se para os cristãos a Bíblia significa um relato histórico verdadeiro, logo, o "passado" contido nas escrituras pode entrar na concepção de "história mestra da vida", podendo - e frequentemente o sendo - uma fonte de lições de vida, comportamentos e práticas. Esse uso dispensa grandes apresentações, afinal, podemos verificá-lo cotidianamente em nossa sociedade, sejam os ensinamentos de amor de Jesus Cristo, seja o uso do Antigo Testamento para condenar os homossexuais, por exemplo. Em O Conto da Aia, Gilead como teocracia cristã utiliza-se vastamente do passado bíblico para estruturar seu regime. No vigésimo nono e trigésimo capítulos de Gênesis, passamos pela história de Jacó, Lia e Raquel.

Nesta passagem, conta-se que Jacó, entre muitas mazelas, casou-se com as irmãs Lia e Raquel. Entre tantas desventuras, Raquel viu-se estéril e, perante a ira de Jacó, ela oferece sua serva, Bila, para que ele tenha filhos. Depois Lia também oferecerá outra serva para coabitar com Jacó. Tal processo deu muitos filhos à ele. Dessarte, não são irrelevantes os principais nomes dos agentes de Gilead: Como já amplamente mencionado, foram os "Filhos de Jacó" que estabeleceram esse regime; e as Aias são disciplinadas no "Centro Raquel e Lia". Ou seja, podemos verificar esse uso do passado na estruturação de um sistema: as Aias são as servas das Esposas inférteis que as oferecem ao marido, o Comandante, para que gerem filhos em seu nome. Mesmo a Cerimônia é montada como na passagem bíblica: 


\section{artigos $\mid e$}

Juliana C. Zanezi

Então se acendeu a ira de Jacó contra Raquel, e disse: Estou eu no lugar de Deus, que te impediu o fruto de teu ventre?

E ela disse: Eis aqui minha serva Bila; coabita com ela, para que dê à luz sobre meus joelhos, e eu assim receba filhos por ela.

$[\ldots]$

Vendo, pois, Lia que cessava de ter filhos, tomou também a Zilpa, sua serva, e deu-a a Jacó por mulher. (GÊNESIS, 30:2-9)

Serena Joy está posicionada, estendida. Suas pernas estão abertas, deito-me entre elas, minha cabeça sobre sua barriga, seu osso púbico sob a base do meu crânio, suas coxas uma de cada lado de mim. [...] Meus braços estão levantados; ela segura minhas mãos, cada uma das minhas numa das delas. Isso deveria significar que somos uma mesma carne, um mesmo ser. [...] Minha saia vermelha é puxada para cima até minha cintura,[...] Abaixo dela, o Comandante está fodendo. (ATWOOD, 2017, p. 114-115)

Como podemos ver, a Cerimônia foi moldada totalmente na história de Raquel e Lia. O uso do passado bíblico aparece também como uma forma de conformar as mulheres envolvidas com a organização dos Filhos de Jacó à situação do uso das Aias: Podemos especular que sem a aderência das Esposas e Tias no sistema montado, ele não seria possibilitado, daí a busca da justificativa na Bíblia. Inclusive, o próprio nome da nova república fundada tem inspiração na vida de Jacó ${ }^{6}$.Paralelamente a isto, podemos verificar outro uso do passado bíblico pelos idealizadores de Gilead, agora do Novo Testamento. No décimo capítulo do livro de Lucas, há uma passagem na qual Jesus Cristo adentra numa aldeia onde foi recebido na casa de duas irmãs, Marta e Maria. Enquanto Maria ouvia a palavra de Jesus, Marta ocupava-se de tarefas domésticas exaustivamente, até que o próprio demanda que ela pare de se preocupar com tais afazeres. Portanto, aqui podemos ver o uso deste trecho dos evangelhos aplicado no cotidiano: Gilead designa as servas domésticas das casas dos Comandantes como "Martas", forçando as mesmas à trabalharem constantemente, exceto durante a pregação da palavra cristã pelo Comandante, antes das Cerimônias. O que é ignorado nessa passagem, é que Jesus era quem estava na casa de Marta e não o contrário; no entanto, a figura de Marta é correntemente associada à mulheres que gostam de realizar

6Gileade foi uma montanha para a qual Jacó fugiu e significa "monte de testemunho", Gênesis 31:21. 


\section{artigos |e}

O Conto da Aia, de Margaret Atwood (1985):

Antiutopia, ovários e uma história social do tempo

serviços domésticos ou o fazem por feliz voluntarismo, o que não é nem de longe o caso das Martas de O Conto da Aia.

É sabido que o uso das escrituras bíblicas são uma forma corrente de legitimar opressões contra mulheres e outros grupos até os dias de hoje, argumentando a vontade de Deus por constarem nos livros. No romance, podemos observar certa lógica em Gilead: se Jacó na Bíblia era um "escolhido" de Deus, os Filhos de Jacó carregaram essa especialidade, constituindo a elite deste regime e, além disso, merecedores de filhos. Daí decorre, por fim, que se sua Esposa não pudesse tê-los, o casal necessitaria de uma "serva", a Aia, para tal tarefa.

Offred também carrega consigo preocupação com seu futuro. Para o sistema, o futuro já está traçado e aparece em outra concepção do feminino dentro da Gilead,

o futuro está nas mãos de vocês, prosseguia Tia Lydia. [...]. Nas mãos de vocês, dizia, e olhava para as próprias mãos, [...] elas estavam vazias. Eram nossas mãos que deviam estar cheias, do futuro; que podia ser pegado, mas não visto. (ATWOOD, 2017, p. 59).

A ideia da figura feminina como redentora e revolucionária não é nova, e remonta a séculos de experiência humana. Encarnada, dentre outras, na figura francesa de Marianne, a mulher seria aquela responsável por transformar o mundo, levá-lo a um novo momento, estágio ou condição de sua história: o símbolo de um futuro melhor, mais próspero e de sucesso (PERROT, 1992, p. 168-170). Essa elaboração aparece em Gilead sobre a perspectiva de um futuro baseado na geração de crianças saudáveis. Já vimos anteriormente (ao analisar um trecho da página 195 do livro) que as Tias ensinam as futuras Aias que no futuro, quando a população voltar a crescer como esperado, as coisas vão mudar e que tudo será melhor, só dependendo do bom trabalho delas. Novamente, uma idealização do feminino que deveria empoderar as mulheres, sendo voltada contra elas. 


\section{artigos}

Juliana C. Zanezi

Um dos momentos mais curiosos no relato de Offred sobre sua preocupação com o futuro ocorre quando ela tem contato com uma foto de sua filha que vivia com outra família. Ao contemplar o crescimento da mesma, ela pensa que preferiria não tê-la visto, pois, a foto Ihe traz a ideia de que

haverá álbuns de família, com todas as crianças neles; nenhuma aia, contudo. Do ponto de vista da história futura, invisíveis [...]. Fui obliterada por ela. Sou apenas uma sombra [...] de uma seremos sombra, como se tornam mães mortas." (ATWOOD, 2017, p. 270-271)

Assim, Offred se sente apagada da história no futuro. Essencial agora, para ter filhos, mas descartada nas fotos. Aias esquecidas pelas famílias e removidas da vida de crianças que geraram e nunca conhecerão. Sujeitos apagados dos registros da cultura material. Ou pelo menos nisso acreditamos até as "Notas Históricas". Pois descobrimos ali que tudo que lemos no romance até este momento constituía uma transcrição das gravações de Offred, organizadas por historiadores de anos muito futuros aos dela. Seu relato tratado como fonte primária para estudo do período gileadiano, que foi “[...] responsável como foi, em última instância, de resenhar o mapa do mundo especialmente neste hemisfério. [...]" (ATWOOD, 2017, p. 351). Ou seja, seu relato acaba sendo essencial entre os escassos resquícios do período, colocando as Aias como protagonistas da história de um período no qual eram silenciadas.

É significativo verificar que mesmo com todos os acontecimentos narrados e com um aparente futuro melhor, "mais civilizado", após Gilead o caráter sexista da sociedade persiste. O professor Piexoto, responsável pelo manejo da fonte, faz algumas piadas de extremo mal gosto durante sua palestra intitulada "Problemas de autenticação com relação ao ‘O conto da aia"' (e que corresponde à quase a totalidade o epílogo). Por exemplo, a associação do termo inglês "Tale" (no original, The Handmaid's Tale) com o sentido vulgar de "tail": "O Rabo da Aia", segundo ele “[...] por assim dizer, o pomo da discórdia naquela fase da sociedade de Gilead [...]" (ATWOOD, 2017, p. 353), e colocado aqui como tom de chacota entre ele e seu colega, também historiador Wade e gerando risos em sua plateia. 


\section{artigos | e}

O Conto da Aia, de Margaret Atwood (1985):

Antiutopia, ovários e uma história social do tempo

Com familiaridade e convivência em um espaço universitário e acadêmico sexista e preconceituoso dos anos setenta e oitenta, Atwood também usa esse epílogo para criticar a posição do mesmo dentro do processo de reinvenção e remodelação de imaginários sobre alguns aspectos da sociedade. Ao tratar de tais fontes com tanta frieza e fazendo piadas com uma situação de horror infligida a outras pessoas, um historiador também não seria responsável por reproduzir as opressões? Essa é uma questão importante para a autora e deve ser levada em conta ao pensarmos o ofício desta profissão. Não podemos ignorar que convivemos com esse tipo de atitude frequentemente dentro da academia que, para Atwood, podem agravar uma banalização de experiências terríveis da humanidade. É muito frequente observar o descaso que muitos professores e pesquisadores de História trazem às suas análises e exposições acerca de fontes, principalmente notável quando tratam de momentos históricos delicados como massacres e guerras.

Quantas vezes pudemos nos deparar com algum deles fazendo troça com atrocidades do passado como Piexoto faz no simpósio fictício? Esse tipo de postura do historiador pode colaborar para a progressiva perpetuação de preconceitos e dessensibilização dos momentos históricos, pensando-os quase como uma ficção? Há de se levar em conta que muitos historiadores, por estarem há muito tempo trabalhando com certa temática, tornam-se insensíveis ao seu conteúdo. Muitos até podem "sem querer esquecer" que lidam com fragmentos e resquícios de eventos que foram reais e violentos e, é claro, é uma atitude perigosa: Atwood, com o fictício evento acadêmico e as atitudes dos pesquisadores envolvidos apresentando a violenta repressão ocorrida em Gilead em tom jocoso, ressalta um caráter quase cíclico, mas melhor caracterizado como "pendular" - menos fatalista e conformado -, com seu final dando a entender que a qualquer momento o "pêndulo" poderia retornar à catástrofe, tão "repentinamente" como foi Gilead. E, afinal, qual o papel dos acadêmicos e estudiosos nesse movimento pendular? Será que estamos lutando contra as 


\section{artigos}

Juliana C. Zanezi

ideias violentas ou estamos, de alguma forma, reproduzindo-as? São questões-chave para a autora e acreditamos que devam ser ao ofício do historiador.

\section{CONSIDERAÇÕES FINAIS}

Em considerações finais, julgo válido ressaltar que o romance é uma fonte fértil de concepções temporais e que este trabalho não pretendeu explorar todas elas: na verdade, buscou ser uma abertura inicial para estudos historiográficos acerca deste romance. A investigação e problematização das memórias de Offred e seus significados dentro e fora da narrativa literária e, ao final, como fonte primária para uma fictícia - porém verossímil historiografia especializada, merecem tratamento exclusivo. Outro aspecto que poderia ser vastamente explorado é a questão da modificação dos calendários, seja litúrgico, seja "revolucionário" devido às mudanças realizadas pelos idealizadores de Gilead no que toca comemorações, feriados e mesmo toques de recolher; qualificar a questão da "Noite" como um local-temporal seria muito profícuo também, além de outras noções que caberiam exame mais profundos, não só no campo História Social do tempo, como de outros campos da historiografia.

Pensando na esfera contemporânea, as temáticas abordadas neste romance dos anos oitenta nunca estiveram tão próximas da realidade social vivida recentemente. A grande ascensão da extrema direita conservadora e cristã em diversas partes do mundo trazem os temas de O Conto da Aia cada vez mais ao cotidiano. Nos Estados Unidos - local onde inclusive o romance se passa - a ascensão de Donald Trump, assumidamente machista, racista, autoritário, etc., sua campanha e vitória como presidente trouxe muito destas questões de volta à tona. É considerável que este romance tenha sido adaptado para série de televisão em 2017 conforme comentado anteriormente, fazendo o mesmo voltar às agendas de leituras de grupos interessados em histórias feitas por mulheres e sobre mulheres, dada a atualidade das temáticas abordadas, que apresentam grande verossimilhança com diversas situações vividas e presenciadas por mulheres em todas as partes do mundo. 


\section{artigos}

O Conto da Aia, de Margaret Atwood (1985):

Antiutopia, ovários e uma história social do tempo

No Brasil, entre tantas desventuras na política, o mais recente presidente eleito aparece em vídeos gravados por jornalistas - e, depois, em entrevistas - dizendo que não estupraria uma colega deputada opositora porque "ela é muito ruim", "é muito feia", "não faz seu gênero" e "porque não merece", como se alguma mulher, independentemente de sua aparência merecesse ser estuprada em alguma circunstância. Entre tantas atrocidades proferidas que aludem à tortura e exaltação de governos militares, quando confrontado com a questão de desigualdade salarial entre gêneros ocupando mesmos cargos, ele afirma que mulheres "devem ganhar menos porque engravidam", condicionando o papel da mulher à sua capacidade de gestação - no presente artigo chamado "tempo do útero" - como forma de justificar a repressão e desigualdade.

Afinal de contas, não é coincidência um candidato completamente despreparado e inapto para o cargo de chefe de Estado, porém fortemente autoritário, armamentista, com discurso misógino, racista e anti-minorias ganhe tanta visibilidade e popularizando-se rapidamente entre um grande número de brasileiros. Segundo o Fórum Brasileiro de Segurança Pública e pesquisa feita pelo Datafolha ${ }^{7}$ em 2016, mais de um terço da população brasileira culpa a vítima pelo estupro sofrido. Segundo o Instituto Maria da Penha, destinado à coibir e prevenir as violências contra a mulher, no Brasil a cada dois segundos uma mulher sofre violência física ou verbal; a cada dois minutos, uma mulher é vítima de arma de fogo; a cada vinte dois segundo e meio, uma mulher sofre tentativa de espancamento e/ou estrangulamento ${ }^{8}$.

Assim, Margaret Atwood escreveu O Conto da Aia nos anos oitenta com personagens e sistema político fictícios como um conjunto de representações muito diretas acerca do

7Para mais informações acerca dos números ver: http://agenciabrasil.ebc.com.br/direitos-humanos/noticia/201609/mais-de-um-terco-da-populacao-brasileira-responsabilizam-mulher.

8Esses dados são parte do projeto "Relógios da Violência", baseado em casos encontrados em pesquisa encomendada ao Datafolha em 2017. Especula-se que apenas 10\% dos casos de violência contra a mulher sejam denunciados no Brasil. Disponível em: https://www.relogiosdaviolencia.com.br/ 


\section{artigos}

Juliana C. Zanezi

mundo real tratados de forma anti-utópica, para todos os efeitos, possui uma narrativa ficcional que pode ser muito mais denunciatória que discursos pretensamente diretos sobre o mundo em que vivemos até os dias de hoje. Os usos do passado (principalmente bíblico, no caso) como forma de legitimar um sistema violento e autoritário conversam muito com a sociedade atual dos extremismos; o condicionamento da mulher a seu "papel" e "função social" de reprodução, a misoginia que se tornou "naturalizada" ao cotidiano; o vertiginoso crescimento das ideias autoritárias baseadas em valores pretensamente cristãos, da família, ordem social, progresso e busca por grupo enquanto inimigo universal. Enfim, todas e quaisquer semelhanças das situações descritas na esfera ficcional do romance de Atwood com o mundo real do passado e presente não devem ser consideradas meras coincidências muito pelo contrário.

\section{REFERÊNCIAS BIBLIOGRÁFICAS}

ATWOOD, Margaret. O Conto da Aia. Tradução Ana Deiró. Rio de Janeiro: Editora Rocco, 2017.

BRAUDEL, Fernand. Escritos sobre a História. São Paulo: Perspectiva, 1978.

CLAEYS, G. Dystopias: A Natural History - A Study of Modern Despotism, Its Antecedents, and Its Literary Diffractions. Oxford: Oxford University Press, 2017

CLAEYS, Gregory; SARGENT, Lyman T. The Utopia Reader. Nova York: New York Press, 1999.

ESPINOZA, Ricardo.; VARGAS, Esteban. Tiempo y Edad biológica. Arbor-Ciencia, pensamiento y cultura, v. 179, n. 760, a022, mar. 2013. Disponível em: http://arbor.revistas.csic.es/index.php/arbor/article/view/1563/1618. Acessado em: 02 Out. 2017. 


\section{artigos |e}

O Conto da Aia, de Margaret Atwood (1985):

Antiutopia, ovários e uma história social do tempo

HIRATA, Helena. Gênero, classe e raça - Interseccionalidade e consubstancialidade das relações sociais. Tempo Social - Revista Sociológica da USP, São Paulo, v. 26, n. 1, p. 6173, 2014. Disponível em: https://www.revistas.usp.br/ts/article/viewFile/84979/87743. Acessado em: 21 Nov. 2017

JAMES, Edward. MENDLESOHN, Farah. The Cambridge Companion to Science Fiction. Nova York: Cambridge University Press, 2003.

KOSELLECK, Reinhart. Futuro Passado: Contribuições Semânticas dos tempos históricos. Tradução Wilma Patrícia Maas e Carlos Almeida Pereira. Rio de Janeiro: Contraponto, 2006.

MARGARET ATWOOD OFFICAL WEBSITE, Canadá. Disponível em: http://margaretatwood.ca/. Acessado em: 18 Set. 2017.

MEYERHOFF, Hans. O Tempo na Literatura. Tradução Myriam Campello. Rio de Janeiro: McGraw-Hill do Brasil, 1976.

MUMFORD, Lewis. Histórias das Utopias. Tradução Isabel Donas Botto. Lisboa: Antígona, 2007.

PERROT, Michelle. Os excluídos da história: operários, mulheres e prisioneiros. Tradução Denise Bottman. 2. ed. São Paulo: Paz e Terra, 1992.

THOMPSON, Becky. Multiracial feminism: Recasting the Chronology of Second Wave Feminism. Feminist Studies, Seattle, v. 28, n. 2. p. 337-360, 2002. Disponível em: https://carwseattle.files.wordpress.com/2010/08/1st-sun-multiracial-feminism.pdf. Acessado em: 14 Ago. 2017 


\section{artigos}

Juliana C. Zanezi

TOLAN, Fiona. Feminist utopias and questions of liberty: Margaret Atwood's The Handmaid's Tale as critique of second wave feminism. Women: A Cultural Review, Londres, v. 16, n. 1, p. 18-32, ago. 2005. Disponível em: http://aplitmorse.weebly.com/uploads/1/3/4/9/13497129/feminist utopias.pdf. Acessado em: 10 Ago. 2017. 